\title{
PRODUÇÃO DE ETANOL Á PARTIR DA SACAROSE EXTRAÍDA DA BETERRABA SACARINA
}

\author{
J. C. FERREIRA ${ }^{1}$, . J. M. MARTINS ${ }^{2}$ e J. R.D. FINZER ${ }^{3}$. M.L. BEGNINI ${ }^{4}$ \\ ${ }^{1}$ Universidade de Uberaba, Faculdade de Engenharia Química \\ ${ }^{2}$ Universidade de Uberaba, Faculdade de Engenharia Química \\ ${ }^{3,4}$ Universidade de Uberaba, Faculdade de Engenharia Química \\ E-mail para contato: jade_ferreira@hotmail.com
}

\begin{abstract}
RESUMO - Os biocombustíveis vêm adquirindo grande importância para sociedade do século 21. Devido a este fato o presente trabalho tem por objetivo produzir álcool etílico a partir da sacarose extraída de beterraba sacarina, determinando à proporção de inoculação do mosto à solução de levedura préativada. Na extração da sacarose por desintegração utilizou-se $600 \mathrm{~g}$ de beterraba e $540 \mathrm{~g}$ de água a $25^{\circ} \mathrm{C}$, obtendo após a filtração $996 \mathrm{~g}$ de mosto com $20 \mathrm{Brix}$. $\mathrm{Na}$ etapa da fermentação prepararam-se três amostras de $200 \mathrm{~g}$, onde se variou a proporção de inoculação da solução de fermento no mosto. Na primeira amostra foi adicionado $20 \%$ de solução de fermento e $80 \%$ de solução de sacarose. $\mathrm{Na}$ segunda amostra utilizou-se $30 \%$ da solução de fermento e $70 \%$ da solução de sacarose. Na terceira amostra foi adicionado $40 \%$ da solução de fermento e $60 \%$ da solução de sacarose. As três amostras foram submetidas a fermentação, e posteriormente realizou-se testes de teor alcoólico, Brix e densidade. Com os valores obtidos calculou-se a produtividade onde ficou evidenciado que a melhor proporção de inoculação foi a utilizada na segunda amostra.
\end{abstract}

\section{INTRODUÇÃO}

Os biocombustíveis, combustíveis de origem vegetal ou animal, produzidos partir da biomassa, ganham cada vez mais destaque e importância no mundo atual onde se há uma grande necessidade de desenvolvimento de forma sustentável. Em 1973 devido a crise do petróleo, ressurge a procura por novas fontes de energia. Nessa época o Brasil importava cerca de $80 \%$ do combustíveis para o seu consumo energético, então para conter a crise o governo cria o programa de substituição do diesel, do óleo combustível e da gasolina por biocombustíveis. Foi lançado no Brasil em 1975 Programa Nacional do Álcool (Proálcool), considerado o maior programa comercial de uso de biomassa para fins energéticos no mundo, com função de regulamentar o uso de álcool anidro a gasolina para reduzir a importação de óleo cru (VIEIRA, 2002).

No Brasil a principal matéria prima utilizada para produção de etanol é a cana-deaçúcar, pois esta apresenta grandes teores de sacarose. Mas equipando-se a cana a beterraba sacarina, cultura largamente utilizada na Europa, essa também apresenta altos teores de sacarose. O processo produtivo de etanol a partir da sacarose extraída da beterraba sacarina se assemelha ao processo utilizado para produzir etanol utilizando cana-de-açúcar, sendo os subprodutos da extração da beterraba o melaço e a polpa (EMBRAPA 2007). 
A beterraba sacarina (Beta Vulgaris) é uma planta dicotiledonea da família das quenopodiáceas, uma planta adaptada ao clima temperado. A planta contém em suas raízes uma elevada concentração de sacarose (GARDÉ, 1978). A nutrição do solo para produção da cultura afetará de maneira direta na quantidade e qualidade do produto final obtido, sendo necessário o conhecimento prévio do solo e das necessidades da cultura a ser desenvolvida. Segundo Tivelli et al. (2011) a produtividade de beterraba quando utilizado doses de nitrogênio (0 a $200 \mathrm{~kg}$ ha-1) na forma de sulfato de amônio aumentam, o valor máximo das raízes de beterraba. A beterraba sacarina por apresentar altos teores de sacarose na faixa de 16 a $21 \%$ consiste numa possível alternativa a produção de etanol no Brasil. Devido a este fato o presente trabalho tem por objetivo produzir álcool etílico por processo fermentativo a partir da sacarose extraída da beterraba sacarina determinando a proporção de inoculação do mosto a solução de levedura pre-ativada visando obter um maior rendimento alcoólico no final do processo.

\section{MATERIAIS E MÉTODOS}

Para produção do álcool etílico, a partir da sacarose extraída da beterraba sacarina, por meio fermentativo, fez necessário realizar o plantio de sementes de beterraba visando a obtenção de matéria-prima para o experimento. Testes práticos e estudo bibliográfico evidenciaram a necessidade de adubação do solo para melhor resultado do plantio, os pesquisadores usaram sulfato de amônio e e adubação orgânica de origem animal (TIVELLI, 2011). A figura 1 ilustra a planta e a figura 2 ilustra a própria beterraba.

Figura 1 - A planta.

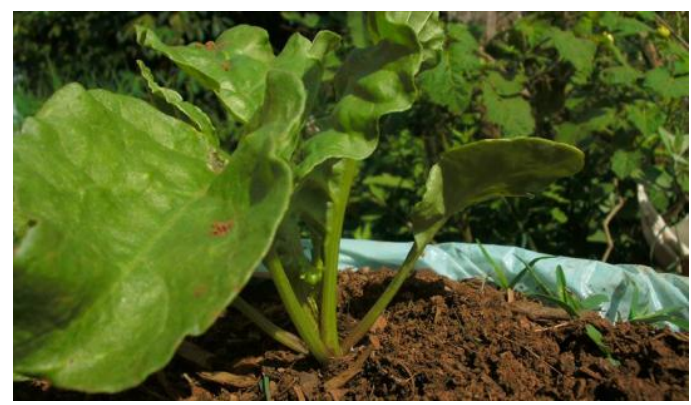

Figura 2- beterraba sacarina

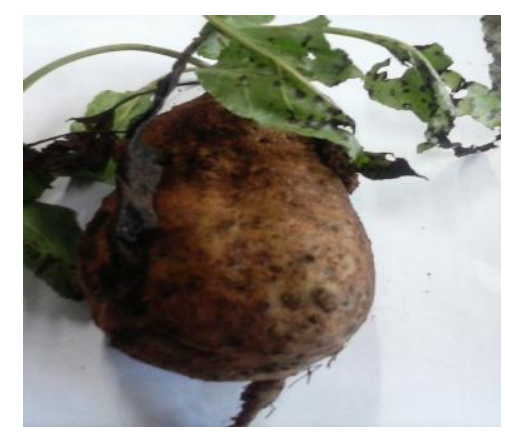


Na extração da sacarose da beterraba Sacarina, utilizou-se $600 \mathrm{~g}$ de beterraba para 540 g de agua os quais foram submetidos a desintegração mecânica estando a agua a $25^{\circ} \mathrm{C}$ suficiente para formação de uma polpa homogênea (FERREIRA,2015). O mosto obtido foi submetido a fermentação.

\subsection{Etapa de fermentação}

O restando do mosto foi submetido a fermentação, preparou-se a solução de fermento, onde foi adicionado $10 \mathrm{~g}$ da levedura Saccharomyce cerevisiae de marca Fleischmann a 100 $\mathrm{mL}$ de agua aquecida a $40^{\circ} \mathrm{C}$. A mistura foi mantida nessa temperatura por $2 \mathrm{~h}$ visando a préativação das leveduras (ANDRIETTA, 2014). Na etapa de fermentação foram preparadas 3 amostras de $200 \mathrm{~g}$, onde variou-se a proporção da solução de fermento e do mosto obtido na extração, visando determinar a proporção. de mosto em que se obtém o maior rendimento alcóolico após a fermentação.

$\mathrm{Na}$ amostra 1 foi adicionado $20 \%$ de solução de fermento- e $80 \%$ de solução de sacarose, ou seja adicionou-se $40 \mathrm{~g}$ de solução de fermento a $160 \mathrm{~g}$ de solução de sacarose. A amostra 2 foi preparada com 30\% da solução de fermento e $70 \%$ da solução de sacarose, ou seja inoculou-se em $140 \mathrm{~g}$ de solução de sacarose com $60 \mathrm{~g}$ de solução de fermento. Já amostra 3 foi adicionado $40 \%$ da solução de fermento e $60 \%$ da solução de sacarose, ou seja foi inoculado 120 de solução de sacarose com $80 \mathrm{~g}$ de solução de fermento com. A três amostras foram mantidas na etapa da fermentação por $48 \mathrm{~h}$.

Após o período de fermentação foram realizados testes de densidade, teor alcóolico e Brix nas três amostras, que posteriormente foram submetidas a destilação fracionada. $\mathrm{O}$ material obtido na destilação e o resíduo da operação também foram submetidos a análise de densidade e teor alcóolico.

\section{RESULTADOS E DISCUSSÕES}

No plantio das sementes de beterraba sacarina obteve-se uma melhora na germinação após a correção solo, onde das 10 sementes plantadas 7 germinaram. Antes da correção do solo de 10 sementes plantadas apenas 3 germinaram (FERREIRA, 2015). A solução obtida na extração da sacarose foi filtrada utilizando um filtro de algodão, onde obteve-se $996 \mathrm{~g}$ de mosto com Brix de 20 , restando $130 \mathrm{~g}$ de borra. 


\subsection{Etapa de fermentação}

Após o período de fermentação realizou-se analises de densidade, teor alcoólico e Brix nas 3 amostras, os resultados obtidos foram organizados na Tabela 1.

Tabela 1- Resultados das analises nas amostras após a fermentação

\begin{tabular}{|l|c|c|c|}
\hline Amostras & $\begin{array}{c}\text { Densidade } \\
(\mathbf{g} / \mathbf{m l})\end{array}$ & $\begin{array}{c}\text { Teor } \\
\text { alcoólico } \\
\text { (gl) }\end{array}$ & Brix \\
\hline Amostra 1 & $0,9914 \mathrm{~g} / \mathrm{ml}$ & $9 \mathrm{GL}$ & 2,3 \\
\hline Amostra 2 & $0,99246 \mathrm{~g} / \mathrm{ml}$ & $8 \mathrm{GL}$ & 2 \\
\hline Amostra 3 & $0,99323 \mathrm{~g} / \mathrm{ml}$ & $7 \mathrm{GL}$ & 2,1 \\
\hline
\end{tabular}

Utilizando os dados obtidos das analises no material após a fermentação realizou-se os cálculos de produtividade, para determinação da amostra em que se obteve o maior rendimento alcoólico.

\subsection{Calculo da produtividade para Amostra 1}

$$
\mathrm{P} \equiv \frac{D \cdot V 1 \cdot A M}{V s}
$$

Onde

$\mathrm{D} \equiv$ Densidade $(\mathrm{g} / \mathrm{ml})$

$\mathrm{V} 1 \equiv$ Volume da solução fermentada (ml)

$\mathrm{AM} \equiv$ Porcentagem de álcool em massa.

Vs $\equiv$ Volume de solução de sacarose utilizada na inoculação com o fermento(L)

$$
\mathrm{P} \equiv \frac{0,9914 \cdot 191 \cdot 0,072}{0,16} \equiv 85,2 \mathrm{~g} \text { álcool/ L de solução }
$$

\subsection{Calculo da produtividade para Amostra 2}

$$
\mathrm{P} \equiv \frac{D \cdot V 1 \cdot A M}{V s}
$$


$\mathrm{P} \equiv \frac{0,99246 \cdot 196 \cdot 0,064}{0,14} \equiv 88,9 \mathrm{~g}$ álcool/ L de solução

\subsection{Calculo da produtividade para Amostra 3}

$$
\begin{aligned}
& \mathrm{P} \equiv \frac{D \cdot V 1 \cdot A M}{V s} \\
& \mathrm{P} \equiv \frac{0,99323 \cdot 192 \cdot 0,055}{0,12} \equiv 87,4 \mathrm{~g} \text { álcool/ L de solução }
\end{aligned}
$$

Portanto a Amostra que maior obteve produtividade foi a Amostra 2 , onde inoculouse $30 \%$ de solução de fermento com $70 \%$ de solução de sacarose, o que fica evidenciado no Gráfico 1.

Gráfico 1 - Gráfico da produtividade das Amostras

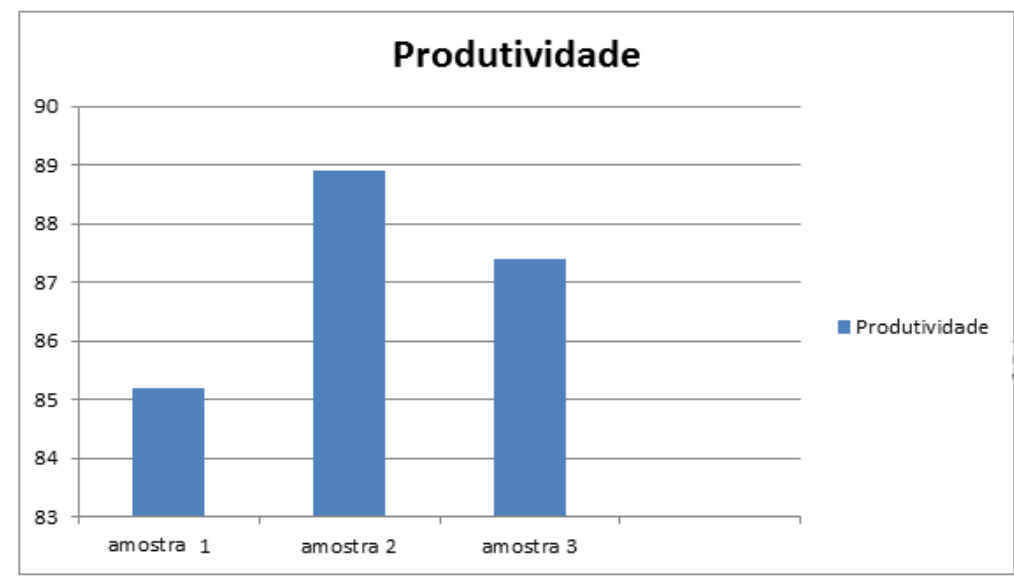

\subsection{Etapa de destilação}

As amostras obtidas na fermentação foram submetidas a destilação fracionada. $\mathrm{O}$ material destilado das três amostras foram submetidos a analises de densidade, teor alcoólico, os dados obtidos foram organizados na Tabelas 2 .

Tabela 2- Resultados dos destilados das amostras após a Destilação.

\begin{tabular}{|c|c|c|}
\hline Amostra & Densidade (g/ml) & Teor alcoólico (GL) \\
\hline Amostra 1 & 0,90207 & 63,8 \\
\hline Amostra 2 & 0,9622 & 31,4 \\
\hline Amostra 3 & 0,9679 & 26,7 \\
\hline
\end{tabular}




\section{CONCLUSÃO}

Após a correção do solo obteve-se uma melhora na germinação das sementes. No processo fermentativo, obteve-se que a amostra que apresentou maior produtividade, foi com utilização de $30 \%$ de solução de levedura para $70 \%$ de mosto, sendo essa a proporção de inoculação mais utilizada nas industrias. Portanto a beterraba sacarina consiste em uma possível alternativa para produção de álcool etílico, tendo ainda alguns obstáculos a serem superados, entre eles o menor ganho energético com a queima do bagaço resultante do processo produtivo, evidenciando a necessidade de direcionar estudos para superar tais obstáculos. Deve-se ressaltar que a beterraba sacarina apresenta uma grande concentração de sacarose, tendo portanto um grande potencial energético.

\section{Referencias}

ANDRIETTA, Silvio. Comunicação pessoal.2014

EMBRAPA. Biocombustíveis. São Paulo: Setprint Gráfica e Editora, 2007. 45 p.

FERREIRA, Jade Carvalho. Fermentação de sacarose extraída da Beterraba Sacarina (Beta Vulgaris L.). In: ENCONTRO TECNOLÓGICO (ENTEC), 9., 2015, Uberaba. Anais... . Uberaba: Uniube, 2015. v. 1, p. 1 - 4.

GARDÉ, Alberto H.. Beterraba sacarina. 5. ed. Santelmo: Agricultura Moderna, 1978. 94 p.

TIVELLI, Sebastião Wilson et al. Beterraba: Do plantio a comercialização. Campinas: Instituto Agronômico, 2011. 45 p.

VIEIRA, Maria Célia Azeredo. Setor Sucroalcooleiro Brasileiro: Evolução e Perspectivas. BNDES, 2002. 40 p. 